\title{
On Budget Deficit under Economic Growth: Towards a Mathematical Model of MMT
}

\author{
Yasuhito Tanaka (Corresponding author) \\ Faculty of Economics, Doshisha University, Kamigyo-ku, \\ Kyoto, 602-8580, Japan \\ E-mail: ochibocho@gmail.com
}

Received: Oct. 30, 2021 Accepted: Dec. 10, $2021 \quad$ Published: Dec. 19, 2021

doi:10.5296/ijssr.v10i1.19130 URL: https://doi.org/10.5296/ijssr.v10i1.19130

\begin{abstract}
Recently, a school of thought called Modern Monetary Theory (MMT) has been attracting attention, but it has not received much theoretical or mathematical analysis. In this paper, we examine the theoretical validity of the MMT argument using an overlapping generations (OLG) model that includes economic growth due to population growth, and give a generally positive evaluation of MMT. The basic idea is that a certain level of continuous budget deficit is necessary to maintain full employment when the economy is growing, that inflation occurs when the budget deficit exceeds that level, that a recession occurs when the budget deficit falls below that level, and involuntary unemployment occurs. In order to recover from a recession, a budget deficit in excess of that level is required, and that deficit need not be covered by a future budget surplus. The same can be said for growth resulting from technological progress.
\end{abstract}

Keywords: overlapping generations (OLG) model, monopolistic competition, full employment, budget deficit, economic growth, inflation, MMT 


\section{Introduction}

Using a simple overlapping generations (OLG) model in which goods are produced solely by labor in a monopolistically competitive industry, this paper shows that maintaining full employment at constant prices in a growing economy with a growing population requires running a continuous budget deficit. Since budget deficits must be sustained, they should be financed by seigniorage rather than debt where institutionally feasible. The need for budget deficits in a growing economy is thought to be due to the fact that older generations have lower total incomes than younger generations and have less total savings available for consumption. This budget deficit is not a debt and should not be repaid or redeemed.

If the budget deficit becomes excessive, inflation will be triggered. Since full employment is maintained by continuous budget deficits, it is only necessary to reduce the excess part of the budget deficit, and there is no need to make up for it later by running a budget surplus or reducing the deficit. Furthermore, if the budget deficit is insufficient, involuntary unemployment will occur, and a larger-than-normal budget deficit will be needed to eliminate it and return to full employment, but there is no need to make up for this later.

This paper is an attempt to provide a theoretical basis for the so-called functional finance theory by Lerner $(1943,1944)$, as well as a theoretical basis for the recently discussed MMT (Modern Monetary Theory, Wray (2015), Mitchell, Wray and Watts (2019)). In particular, this paper provides an argument for the following claim (Kelton (2020)). We refer here to Hogan's summary of Kelton's book (Hogan (2021)). In fact, Hogan criticizes "Kelton is wrong" (Note 1 ), but he summarizes the main points of the argument in a good way.

\section{The US Treasury creates new money.}

Since consumers save with money, and since money supply equals savings, an increase in money supply equals an increase in savings. As equation (5) in Section 5.2 shows, the increase in savings equals the budget deficit. Since the rate of increase in savings equals the rate of increase in money, which equals the rate of economic growth, i.e., the rate of increase in the production of goods, the increase in the money supply does not cause inflation.

2. Inflation is caused by federal government deficit spending, not by Fed policy.

As will be shown in Section 5.3, if the actual budget deficit is larger than the budget deficit necessary and sufficient to maintain full employment under economic growth, the price of goods will rise.

3. Federal government spending is not related to taxes or borrowing.

As mentioned above, in order to achieve full employment under economic growth, continuous budget deficit is necessary. In a growing economy, it is not possible to maintain full employment through balanced budget. Therefore, even if the budget deficit to maintain full employment is financed by government debt, it does not have to be repaid or redeemed, nor does it have to be covered by future budget surpluses. The same is true for the additional budget deficit required to eliminate involuntary unemployment caused by insufficient budget deficit and return to full employment. 
In Appendix B, using a three generations OLG model we briefly consider the case where there is a pay-as-you-go pension and consumption in childhood period, and show that in order to maintain full employment under economic growth, a budget deficit is necessary if the difference between savings excluding pensions and the debt from childhood consumption is positive, and that an excessive budget deficit leads to inflation. In Appendix C, we review the money flows for a model with pensions and consumption in the childhood period.

The same conclusion can be reached in the case of economic growth resulting from technological progress rather than from population growth. The model and analysis are almost identical, and the only difference is in the interpretation, which we will briefly discuss in Section 6.

In this paper, we assume that labor productivity is affected by the amount of employment but not by population growth itself in the case of increasing or decreasing returns to scale, but we also briefly discuss the case where productivity changes at a rate greater than or less than the rate of population growth due to increasing or decreasing returns to scale in the last section.

\section{The Model}

According to Otaki (2007, 2009, 2015a, 2015b), we use a two-periods (two-generations) overlapping generations (OLG) model with production of goods under monopolistic competition. Two periods are Period 1 (younger or working period) and Period 2 (older or retired period). The structure of the model is as follows.

1. Labor is only the factor of production. The goods constitute a continuum of $[0,1]$. Each good is denoted by index $z \in[0,1]$. Good $z$ is monopolistically produced by Firm $z$ with increasing or decreasing returns to scale technology. Under increasing or decreasing returns to scale employment and output may affect the labor productivity. However, we assume that population growth itself does not affect the labor productivity, and in the full employment state population and output increases at the same rate.

2. In Period 1 consumers supply labor, consume the goods and save money for consumption in Period 2. They are employed or unemployed.

3. In Period 2 consumers consume the goods by their savings carried over from the previous period.

4. Each consumer determines his/her consumption and labor supply in the beginning of their Period 1 corresponding to the situation where he is employed or unemployed.

The notation of this paper is as follows.

$C_{i}^{e}$ : consumption basket of an employed consumer in Period $i, i=1,2$.

$C_{i}^{u}$ : consumption basket of an unemployed consumer in Period $i, i=1,2$.

$c_{i}^{e}(z)$ : demand for good $\mathrm{z}$ of an employed consumer in Period $i, i=1,2$.

$c_{i}^{u}(z)$ : demand for good $\mathrm{z}$ of an unemployed consumer in Period $i, i=1,2$. 
$P_{i}$ : the price of the consumption basket in Period $i, i=1,2$.

$p_{i}(z)$ : the price of good $\mathrm{z}$ in Period $i, i=1,2$.

$\rho=P_{2} / P_{1}$ : expected inflation rate $(+1)$.

$W$ : the nominal wage rate.

$\Pi$ : profit of firms which is equally distributed to the younger generation consumers.

$l$ : individual labor supply.

$\Gamma(l)$ : disutility of labor which is increasing in $l$ and strictly concave.

$L$ : total employment.

$L_{f}$ : labor population, or employment in the full employment state. It increases at the rate $\gamma-1>0$. If population in Period $t$ is $L_{f}$, the population in Period $t+1$ is $\gamma L_{f}$.

$y$ : labor productivity which is increasing (increasing returns to scale case) or decreasing (decreasing returns to scale case) in the total employment $L l$. It is not affected by population growth (in the last section we consider a case where labor productivity changes by population growth).

\section{Utility Maximization of Consumers}

The utility function of an employed consumer is

$$
u\left(C_{1}^{e}, C_{2}^{e}\right)-\Gamma(l) .
$$

$u(\cdot, \cdot)$ is homothetic. $\Gamma(l)$ is disutility of labor. The utility function of an unemployed consumer is

$$
u\left(C_{1}^{u}, C_{2}^{u}\right)
$$

The consumption baskets in Period $i$ for employed and unemployed consumers are

$$
\begin{aligned}
& C_{i}^{e}=\left(\int_{0}^{1} c_{i}^{e}(z)^{\frac{\sigma-1}{\sigma}} d z\right)^{\frac{\sigma}{\sigma-1}}, i=1,2, \\
& C_{i}^{u}=\left(\int_{0}^{1} c_{i}^{u}(z)^{\frac{\sigma-1}{\sigma}} d z\right)^{\frac{\sigma}{\sigma-1}}, i=1,2 .
\end{aligned}
$$

$\sigma$ is the elasticity of substitution of the goods. It satisfies $\sigma>1$.

The price of the consumption basket in Period $i$ is

$$
P_{i}=\left(\int_{0}^{1} p_{i}(z)^{1-\sigma} d z\right)^{\frac{1}{1-\sigma}}, i=1,2
$$

The budget constraint for an employed consumers is

$$
\int_{0}^{1} p_{1}(z) c_{1}^{e}(z) d z+\int_{0}^{1} p_{2}(z) c_{2}^{e}(z) d z=W l+\Pi
$$


The budget constraint for an unemployed consumer is

$$
\int_{0}^{1} p_{1}(z) c_{1}^{u}(z) d z+\int_{0}^{1} p_{2}(z) c_{2}^{u}(z) d z=\Pi
$$

From calculations in Appendix A, let

$$
\begin{gathered}
\alpha=\frac{P_{1} C_{1}^{e}}{P_{1} C_{1}^{e}+P_{2} C_{2}^{e}}=\frac{P_{1} C_{1}^{u}}{P_{1} C_{1}^{u}+P_{2} C_{2}^{u}} \\
1-\alpha=\frac{P_{2} C_{2}^{e}}{P_{1} C_{1}^{e}+P_{2} C_{2}^{e}}=\frac{P_{2} C_{2}^{u}}{P_{1} C_{1}^{u}+P_{2} C_{2}^{u}},
\end{gathered}
$$

then, the demand functions for consumption baskets of employed and unemployed consumers are

$$
\begin{gathered}
C_{1}^{e}=\alpha \frac{W l+\Pi}{P_{1}}, \quad C_{2}^{e}=(1-\alpha) \frac{W l+\Pi}{P_{2}}, \\
C_{1}^{u}=\alpha \frac{\Pi}{P_{1}}, \quad C_{2}^{u}=(1-\alpha) \frac{\Pi}{P_{2}} .
\end{gathered}
$$

And their demand functions for good $\mathrm{z}$ are

$$
\begin{aligned}
& c_{1}^{e}(z)=\left(\frac{p_{1}(z)}{P_{1}}\right)^{-\sigma} \frac{\alpha(W l+\Pi)}{P_{1}}, \quad c_{2}^{e}(z)=\left(\frac{p_{2}(z)}{P_{2}}\right)^{-\sigma} \frac{(1-\alpha)(W l+\Pi)}{P_{2}}, \\
& c_{1}^{u}(z)=\left(\frac{p_{1}(z)}{P_{1}}\right)^{-\sigma} \frac{\alpha \Pi}{P_{1}}, \quad c_{2}^{u}(z)=\left(\frac{p_{2}(z)}{P_{2}}\right)^{-\sigma} \frac{(1-\alpha) \Pi}{P_{2}} .
\end{aligned}
$$

From these analyses the indirect utility functions of employed and unemployed consumes are

$$
\begin{gathered}
V^{e}=u\left(\alpha \frac{W l+\Pi}{P_{1}},(1-\alpha) \frac{W l+\Pi}{P_{2}}\right)-\Gamma(l), \\
V^{u}=u\left(\alpha \frac{\Pi}{P_{1}},(1-\alpha) \frac{\Pi}{P_{2}}\right) .
\end{gathered}
$$

Let the real wage rate be

$$
\omega=\frac{W}{P_{1}}
$$

The indirect utility functions are written as

$$
\begin{gathered}
V^{e}=\varphi\left(\omega l+\frac{\Pi}{P_{1}}, \rho\right)-\Gamma(l), \\
V^{u}=\varphi\left(\frac{\Pi}{P_{1}}, \rho\right) .
\end{gathered}
$$


Let

$$
I=\omega l+\frac{\Pi}{P_{1}}
$$

Then, given $\rho$, the condition for maximization of $V^{e}$ with respect to $l$ is

$$
\frac{\partial \varphi}{\partial I} \omega-\Gamma^{\prime}(l)=0
$$

where

$$
\frac{\partial \varphi}{\partial I}=\alpha \frac{\partial u}{\partial C_{1}^{e}}+(1-\alpha) \frac{\partial u}{\partial C_{2}^{e}}
$$

Given $P_{1}$ and $\rho$, the labor supply is a function of $\omega$. From (1) we have

$$
\frac{d l}{d \omega}=\frac{\frac{\partial \varphi}{\partial I}+\frac{\partial^{2} \varphi}{\partial I^{2}} \omega l}{\Gamma \prime \prime(l)-\frac{\partial^{2} \varphi}{\partial I^{2}} \omega^{2}} .
$$

If $\frac{d l}{d \omega}>(<) 0$, the labor supply is an increasing (decreasing) function of the real wage rate $\omega$. We assume that the real wage rate does not significantly affect individual labor supply. The labor productivity $l$ may affect employment $L$ in some way. We assume that even in this case $L l$ is an increasing function of $L$.

\section{Profit Maximization of Firms}

Let $d_{1}(z)$ be the demand for good $\mathrm{z}$ in Period 1 of the younger generation consumers. It is

$$
d_{1}(z)=\left(\frac{p_{1}(z)}{P_{1}}\right)^{-\sigma} \frac{\alpha\left(W L l+L_{f} \Pi\right)}{P_{1}}=\left(\frac{p_{1}(z)}{P_{1}}\right)^{-\sigma} \frac{\alpha\left(W L l+L_{f} \Pi\right)}{P_{1}} .
$$

This is the sum of demand of employed consumers and unemployed consumers. Similarly, their demand for good $\mathrm{z}$ in Period 2 is

$$
d_{2}(z)=\left(\frac{p_{2}(z)}{P_{2}}\right)^{-\sigma} \frac{(1-\alpha)\left(W L l+L_{f} \Pi\right)}{P_{2}} .
$$

Let $\overline{d_{2}(z)}$ be the demand for good $\mathrm{z}$ of the older generation consumers. It is

$$
\overline{d_{2}(z)}=\left(\frac{p_{2}(z)}{P_{2}}\right)^{-\sigma} \frac{(1-\alpha)\left(\bar{W} \overline{L l}+L_{f} \bar{\Pi}\right)}{P_{2}}
$$

$\bar{W}, \bar{\Pi}, \bar{L}$ and $\bar{l}$ are the nominal wage rate, profit of firms, employment and individual labor supply in the previous period. Let

$$
M=(1-\alpha)\left(\bar{W} \overline{L l}+L_{f} \bar{\Pi}\right)
$$




\section{Macrothink}

This is the total demand or the total savings of the older generation consumers which is determined in their Period 1. The demand for good $\mathrm{z}$ of the older generation consumers is $\left(\frac{p_{1}(z)}{P_{1}}\right)^{-\sigma} \frac{M}{P_{1}}$.

The government expenditure as well as the consumptions of the younger generation consumers and those of the older generation consumers constitute the national income. The total demand for good $z$ is

$$
d(z)=\left(\frac{p_{1}(z)}{P_{1}}\right)^{-\sigma} \frac{Y}{P_{1}}
$$

$Y$ is the following effective demand.

$$
Y=\alpha\left(W L l+L_{f} \Pi\right)+G+M .
$$

$G$ is the government expenditure. The government determines the demand for good $\mathrm{z}, g(z)$, to maximize

$$
\tilde{G}=\left(\int_{0}^{1} g(z)^{\frac{\sigma-1}{\sigma}} d z\right)^{\frac{\sigma}{\sigma-1}}
$$

under the constraint

$$
\int_{0}^{1} p_{1}(z) g(z) d z=G
$$

Let $L$ and $L l$ be the employment for good $\mathrm{z}$ and "employment $\times$ labor supply". Then, we have

$$
\int_{0}^{1} L d z=L, \int_{0}^{1} L l d z=L l
$$

The output of Firm $z$ is Lly. By increasing or decreasing returns to scale, $y$ is a function of $L l$. Since in the equilibrium $L l y=d(z)$, we obtain

$$
\frac{\partial d(z)}{\partial L l}=y+L l y^{\prime}(L l)
$$

In the case of constant returns to scale,

$$
\frac{\partial d(z)}{\partial L l}=y
$$

From (2)

$$
\frac{\partial p_{1}(z)}{\partial d(z)}=-\frac{p_{1}(z)}{\sigma d(z)}
$$

Therefore, we have 


$$
\frac{\partial p_{1}(z)}{\partial L l}=-\frac{p_{1}(z)[y+L l y \prime(L l)]}{\sigma d(z)}=-\frac{p_{1}(z)}{\sigma L l}\left[1+\frac{L l y \prime(L l)}{y}\right] .
$$

We define the elasticity of the labor productivity by

$$
\zeta=\frac{L l y \prime(L l)}{y} \text {. }
$$

Then,

$$
\frac{\partial p_{1}(z)}{\partial L l}=-\frac{p_{1}(z)(1+\zeta)}{\sigma L l}
$$

$\zeta$ is constant, and satisfies $1+\zeta>0$. For technology with increasing (decreasing) returns to scale, $\zeta>0(\zeta<0)$.

The profit of Firm $\mathrm{z}$ is

$$
\pi(z)=p_{1}(z) L l y-L l W .
$$

From the condition for profit maximization:

$$
\frac{\partial \pi(z)}{\partial L l}=\left[p_{1}(z) y-L l y \frac{p_{1}(z)}{\sigma L l}\right](1+\zeta)-W=\left[p_{1}(z) y-\frac{p_{1}(z) y}{\sigma}\right](1+\zeta)-W=0 .
$$

We obtain

$$
p_{1}(z)=\frac{1}{\left(1-\frac{1}{\sigma}\right)(1+\zeta) y} W
$$

Let $\mu=1 / \sigma$. Then,

$$
p_{1}(z)=\frac{1}{(1-\mu)(1+\zeta) y} W
$$

Thus, the real wage rate equals

$$
\omega=(1-\mu)(1+\zeta) y .
$$

Since all firms are symmetric,

$$
P_{1}=p_{1}(z)=\frac{1}{(1-\mu)(1+\zeta) y} W
$$

for all $\mathrm{z}$.

\section{The Budget Deficit to Maintain Full Employment Under Economic Growth and Inflation by Excessive Budget Deficit}

\subsection{Market Equilibrium}

The nominal total supply is

$$
W L+L_{f} \Pi=P_{1} L l y .
$$


The nominal total demand is

$$
\alpha\left(W L+L_{f} \Pi\right)+G+M=\alpha P_{1} L l y+G+M .
$$

By the equilibrium of them,

$$
P_{1} L l y=\alpha P_{1} L l y+G+M .
$$

In real terms,

$$
L l y=\frac{G+M}{(1-\alpha) P_{1}}
$$

$L l$ is not larger than $L_{f} l\left(L_{f}\right)\left(l\left(L_{f}\right)\right.$ is the labor supply in the full employment state). However, it may be smaller than $L_{f} l\left(L_{f}\right)$. Then, we have $L<L_{f}$, and there exists involuntary unemployment. If the government collects taxes from the younger generation consumers, (3) is written as

$$
P_{1} L l y=\alpha\left(P_{1} L l y-T\right)+G+M .
$$

\subsection{Budget Deficit for Full Employment}

Assume that up to Period $t$ full employment has been maintained under constant price. Then,

$$
P_{1}^{t} L_{f} l\left(L_{f}\right) y=\alpha\left(P_{1}^{t} L_{f} l\left(L_{f}\right) y-T^{t}\right)+G^{t}+M^{t}
$$

Superscript $t$ means the value in Period $t$. The savings of the younger generation consumers is

$$
(1-\alpha)\left(P_{1}^{t} L_{f} l\left(L_{f}\right) y-T^{t}\right)=G^{t}-T^{t}+M^{t}
$$

To maintain full employment under economic growth by population growth this should equal $\gamma M^{t}$. Therefore,

$$
G^{t}-T^{t}=(\gamma-1) M^{t}
$$

$M^{t}$ is the savings and consumptions of the older generation consumers in Period $t$. Since this is positive, we have $G^{t}>T^{t}$ when $\gamma>1$.

In Period $t+1$, we get $M^{t+1}=\gamma M^{t}, G^{t+1}=\gamma G^{t}$ and $T^{t+1}=\gamma T^{t}$. Thus, under the condition that $P_{1}^{t+1}=P_{1}^{t}$,

$$
P_{1}^{t} L_{f} \gamma l\left(L_{f} \gamma\right) y=\alpha\left(P_{1}^{t} L_{f} \gamma l\left(L_{f} \gamma\right) y-\gamma T^{t}\right)+\gamma G^{t}+\gamma M^{t}
$$

$l\left(L_{f} \gamma\right)$ denotes the labor supply under full employment after population increases. Since this is equivalent to (4), $G^{t+1}=\gamma G^{t}, T^{t+1}=\gamma T^{t}$ maintain full employment. Since the budget deficit to maintain full employment must be continuous, it should be financed by seigniorage not government bonds. The reason why budget deficit is necessary in a growing economy is 
as follows. When economy grows, the life time income of the older generation consumers is lower than that of the younger generation consumers. Therefore, their savings and resulting consumption will be insufficient to achieve full employment. This budget deficit is not a debt and should not be redeemed or repaid.

Since consumers save with money, and since the money supply equals savings, an increase in the money supply equals an increase in savings. From (5) we find that an increase in savings equals the budget deficit. Since the rate of increase in savings is equal to the rate of economic growth, the budget deficit in this case will not cause inflation.

Summarizing the results,

Proposition 1 A continuous budget deficit is necessary to maintain full employment when the economy is growing due to population growth under constant prices.

\subsection{Excessive Budget Deficit and Inflation}

Assume that up to Period $t-1$ full employment has been maintained under constant price. However, the government expenditure or tax in Period $t$ is different from the value in the steady state. The steady state means a state where full employment has been maintained under constant price. Let $\hat{G}^{t}$ and $\hat{T}^{t}$ be the actual values of the government expenditure and the tax, $\hat{P}_{1}^{t}$ be the actual value of the price in Period $t$. Then,

$$
\hat{P}_{1}^{t} L_{f} l\left(L_{f}\right) y=\alpha\left(\hat{P}_{1}^{t} L_{f} l\left(L_{f}\right) y-\hat{T}^{t}\right)+\hat{G}^{t}+M^{t}
$$

The savings of the younger generation consumers is

$$
M^{t+1}=(1-\alpha)\left(\hat{P}_{1}^{t} L_{f} l\left(L_{f}\right) y-\widehat{T}^{t}\right)=\hat{G}^{t}-\widehat{T}^{t}+M^{t}
$$

Let

$$
\eta=\frac{\hat{P}_{1}^{t}}{P_{1}^{t}}>1
$$

To maintain full employment in Period $t+1$ under the condition that $P_{1}^{t+1}=\hat{P}_{1}^{t}>P_{1}^{t}$ we need

$$
\hat{G}^{t}-\hat{T}^{t}+M^{t}=\gamma \eta M^{t}
$$

From (5)

$$
\hat{G}^{t}-\hat{T}^{t}=(\gamma \eta-1) M^{t}>(\gamma-1) M^{t}=G^{t}-T^{t} .
$$

(8) means

$$
(\eta-1) \gamma M^{t}=\left(\hat{G}^{t}-\hat{T}^{t}\right)-\left(G^{t}-T^{t}\right)
$$

or

$$
\eta-1=\frac{\left(\hat{G}^{t}-\hat{T}^{t}\right)-\left(G^{t}-T^{t}\right)}{\gamma M^{t}}>0 .
$$




\section{Macrothink}

Therefore, the excessive budget deficit $\left(\hat{G}^{t}-\widehat{T}^{t}\right)-\left(G^{t}-T^{t}\right)$ will cause inflation at the rate of $\eta=\frac{\hat{P}_{1}^{t}}{P_{1}^{t}}$.

Since in Period $t+1$ we have $M^{t+1}=\gamma \eta M^{t}$, and we can assume that $G^{t+1}=\gamma \eta G^{t}$, $T^{t+1}=\gamma \eta T^{t}$

under the condition that $P_{1}^{t+1}=\hat{P}_{1}^{t}$ we have

$$
\hat{P}_{1}^{t} L_{f} l\left(L_{f}\right) \gamma y=\alpha\left(\hat{P}_{1}^{t} L_{f} l\left(L_{f}\right) \gamma y-\gamma \eta T^{t}\right)+\gamma \eta G^{t}+\gamma \eta M^{t} .
$$

Since $\hat{P}_{1}^{t}=\eta P_{1}^{t}$, this is equivalent to (4). Thus, full employment is achieved by $G^{t+1}=$ $\gamma \eta G^{t}$ and $T^{t+1}=\gamma \eta T^{t}$. After one period inflation, we can maintain full employment by continuous budget deficit under constant price. Therefore, the excess budget deficit that caused inflation can be reduced only by reducing the excess part, and there is no need to make up for it by creating a surplus later or by making the budget deficit smaller than the steady state value.

Summarizing the results,

\section{Proposition 2}

1. Inflation is caused when the budget deficit becomes larger than the level necessary and sufficient to maintain full employment.

2. An excess part of excessive budget deficits that cause inflation need only be reduced, and there is no need to make up for the excessive deficit by creating a surplus later or by reducing the budget deficit below its steady-state value.

Suppose that inflation continues in Period $t+1$, and $P_{1}^{t+1}=\eta \hat{P}_{1}^{t}$. Then,

$$
\hat{P}_{1}^{t} L_{f} l\left(L_{f}\right) \gamma \lambda y=\alpha\left(\hat{P}_{1}^{t} L_{f} l\left(L_{f}\right) \gamma \lambda y-\gamma \eta \hat{T}^{t}\right)+\gamma \eta \hat{G}^{t}+\gamma \eta M^{t}
$$

This is equivalent to (7).

As for the process leading to inflation, we can think of a story in which excess demand for goods generates excess demand for labor, which raises the nominal wage rate, which in turn raises the prices of the goods. Assuming that production does not increase above the full employment level, nominal supply and demand will not be balanced unless prices rise.

\subsection{Insufficient Budget Deficit and Involuntary Unemployment}

Suppose that in $L l$ is different from $L_{f} l\left(L_{f}\right)$ in (4), and the government expenditure is different from $G^{t}$. The price of the goods is constant. Let $\hat{G}^{t}$ and $T^{t}$ be the actual values of the government expenditure and the tax. Then, we have

$$
P_{1}^{t} L l(L) y=\alpha\left(P_{1}^{t} L l(L) y-T^{t}\right)+\hat{G}^{t}+M^{t} .
$$

Comparing (9) and (4), 


$$
L l(L)-L_{f} l\left(L_{f}\right)=\frac{\hat{G}^{t}-G^{t}}{(1-\alpha) P_{1}^{t} y}
$$

$L<L_{f}$ when $\hat{G}^{t}<G^{t}$. Thus, insufficient government expenditure will cause involuntary unemployment.

As clarified in Proposition 1, budget deficit is necessary to maintain full employment when the economy is growing, so involuntary unemployment will occur under balanced budget condition.

The savings of the younger generation consumers in Period $t$ is

$$
\widehat{M}^{t+1}=(1-\alpha)\left(P_{1}^{t} L l(L) y-T^{t}\right)=\widehat{G}^{t}-T^{t}+M^{t} .
$$

This equals the consumption of the older generation consumers in Period $t+1$. Assume that in Period $t+1$ full employment is achieved under the condition that $P_{1}^{t+1}=P_{1}^{t}$, $T^{t+1}=\gamma T^{t}$. Then,

$$
P_{1}^{t} L_{f} \gamma l\left(L_{f} \gamma\right) y=\alpha\left(P_{1}^{t} L_{f} \gamma l\left(L_{f} \gamma\right) y-\gamma T^{t}\right)+\hat{\hat{G}}^{t+1}+\widehat{M}^{t+1} .
$$

$\hat{\hat{G}}^{t+1}$ is the actual value of the government expenditure in Period $t+1$. The savings of the younger generation consumers in Period $t+1$ is

$$
\begin{aligned}
M^{t+2} & =(1-\alpha)\left(P_{1}^{t} L_{f} \gamma l\left(L_{f} \gamma\right) y-\gamma T^{t}\right)=\hat{\hat{G}}^{t+1}-\gamma T^{t}+\widehat{M}^{t+1} \\
& =\hat{\hat{G}}^{t+1}-\gamma T^{t}+\hat{G}^{t}-T^{t}+M^{t}
\end{aligned}
$$

This must equal $\gamma^{2} M^{t}$ to achieve full employment. Note $M^{t}$ is the steady state value of the savings of the younger generation consumers in Period $t$. Therefore,

$$
\hat{\hat{G}}^{t+1}-\gamma T^{t}+\hat{G}^{t}-T^{t}=\left(\gamma^{2}-1\right) M^{t}=\gamma(\gamma-1) M^{t}+(\gamma-1) M^{t} .
$$

In the steady sate

$$
\begin{aligned}
& \hat{G}^{t+1}=\gamma G^{t}, \hat{G}^{t}=G^{t}, \\
& \hat{G}^{t}-T^{t}=(\gamma-1) M^{t},
\end{aligned}
$$

and

$$
\hat{\hat{G}}^{t+1}-\gamma T^{t}=\gamma(\gamma-1) M^{t}
$$

hold. If $\hat{G}^{t}<G^{t}$, we have 


$$
\hat{G}^{t}-T^{t}<(\gamma-1) M^{t}
$$

Thus, we need

$$
\hat{\hat{G}}^{t+1}-\gamma T^{t}>\gamma(\gamma-1) M^{t}
$$

Therefore, the additional budget deficit larger than the steady state value is necessary to restore full employment in Period $t+1$. Summarizing the results.

Proposition 3 Insufficient government expenditure in Period $t$ causes involuntary unemployment, and an additional budget deficit above the steady-state value is needed to restore full employment in period $t+1$.

Since a continuous budget deficit is required after full employment is restored as shown in Proposition 1, the additional budget deficit created to overcome the recession does not have to be made up by later surpluses.

In this section, prices were assumed to be constant. If involuntary unemployment leads to a fall in the nominal wage rate, which in turn leads to a fall in prices, then the real balance effect (so-called Pigou effect) may kick in and increase consumption. However, the use of fiscal policy would be more likely to bring about a rapid return to full employment.

\section{Growth by Technological Progress and a Case Where Population Growth Affect the Labor Productivity}

(1) In a case of growth by technological progress not population growth, $L_{f}$ is constant and $y$ increases at the rate $\gamma-1$. Then, by interpreting $\gamma$ as being multiplied by $y$ instead of being multiplied by $L_{f}$, basically all the equations are still valid. But $l\left(L_{f} \gamma\right)$ (labor supply in a state of full employment) in (6), (11), (12), and (B.4), (B.5) in Appendix B below should be written as $l\left(L_{f}\right)$.

(2) We assume that the labor productivity in each period depends on the amount of employment in the case of increasing and decreasing returns to scale, but that population growth itself has no effect on productivity. In the following, I will briefly explain the case in which population growth affects productivity.

Assume that $l\left(L_{f}\right)$ and $l\left(L_{f} \gamma\right)$ are equal, and denote them by $l$. If full employment is achieved, the labor productivity $y\left(L_{f} \gamma l\right)$ in Period $t+1$ and that in Period $t y\left(L_{f} l\right)$ satisfy

$$
y\left(L_{f} \gamma l\right)=y\left(L_{f} l\right)+y^{\prime}\left(L_{f} l\right) L_{f} l(\gamma-1)=y\left(L_{f} l\right)[1+\zeta(\gamma-1)] .
$$

Then, replacing $\gamma$ by

$$
\gamma^{\prime}=\gamma[1+\zeta(\gamma-1)]
$$

(5) is rewritten as

$$
G^{t}-T^{t}=\left(\gamma^{\prime}-1\right) M^{t} .
$$

Similarly, let $G^{t+1}=\gamma^{\prime} G^{t}, T^{t+1}=\gamma^{\prime} T^{t},(6)$ is rewritten as 


$$
P_{1}^{t} L_{f} \gamma^{\prime} l y=\alpha\left(P_{1}^{t} L_{f} \gamma^{\prime} l y-\gamma^{\prime} T^{t}\right)+\gamma^{\prime} G^{t}+\gamma^{\prime} M^{t}
$$

This is equivalent to (4). In (8), replacing $\gamma \eta$ by $\gamma[1+\zeta(\gamma-1)] \eta=\gamma^{\prime} \eta$, we obtain the result that inflation occurs at the rate of $\eta \cdot \eta-1$ equals

$$
\frac{\left(\hat{G}^{t}-\hat{T}^{t}\right)-\left(G^{t}-T^{t}\right)}{\gamma^{\prime} M^{t}} \text {. }
$$

Replacing $\gamma$ by $\gamma^{\prime}=\gamma[1+\zeta(\gamma-1)]$, all arguments from (11), (12) to Proposition 3 hold. The arguments after (B.4), (B.5) in Appendix B below are similar.

Therefore, in a case where population growth affects the labor productivity, let $\zeta$ be the elasticity of the labor productivity, the rate of economic growth is

$$
\gamma^{\prime}-1=\gamma[1+\zeta(\gamma-1)]-1 .
$$

In the case of increasing returns to scale, the economy grows at a rate greater than the rate of population growth, and in the case of decreasing returns to scale, the economy grows at a rate less than the rate of population growth.

In this paper, we did not consider the existence of capital in production and investment by firms. In the future, we would like to create a model that includes these factors and study the problem of the interest rate. However, the position that fiscal policy, not monetary policy, should play the main role of achieving and restoring full employment without causing inflation will not change.

\section{Concluding Remarks}

The purpose of this paper was to provide a theoretical analysis of MMT and Functional Finance Theory based on mathematical models, while taking into account microeconomic foundations about the behavior of consumers and firms.

The main conclusions are that a certain level of continuous budget deficit is necessary to maintain full employment under economic growth, that a budget deficit above that level causes inflation, and a budget deficit below that level causes a recession including involuntary unemployment.

The basic two-generation overlapping model with monopolistic competiton about production of the goods was used, but it was shown that essentially the same conclusions could be reached by using a model that includes a pay-as-you-go pension system and unemployment insurance, or by using a three-generation model that includes the childhood period before the consumers work. Please see Appendix B.

\section{Acknowledgement}

We thank the editor and the reviewers for their thorough reviews and highly appreciate the comments and suggestions, which significantly contributed to improving the quality of the publication. This work was supported by JSPS KAKENHI Grant Number 18K01594 in Japan. 


\section{References}

Hogan, T. (2021). Review of Stephanie Kelton's the Deficit Myth. AIER Sound Money Project Working Paper No. 2021-5. https://doi.org/10.2139/ssrn.3767562

Kelton. S. (2020). The Deficit Myth: Modern Monetary Theory and the Birth of the People's Economy. Public Affairs.

Lerner, A. P. (1943). Functional finance and the federal debt. Social Research, 10, 38-51.

Lerner, A. P. (1944). The Economics of Control: Principles of Welfare Economics. Macmillan.

Mitchell, W., Wray, L. R., \& Watts, M. (2019). Macroeconomics. Red Globe Press.

Otaki, M. (2007). The dynamically extended Keynesian cross and the welfare-improving fiscal policy. Economics Letters, 96, 23-29. https://doi.org/10.1016/j.econlet.2006.12.005

Otaki, M. (2009). A welfare economics foundation for the full-employment policy. Economics Letters, 102, 1-3. https://doi.org/10.1016/j.econlet.2008.08.003

Otaki, M. (2015a). Keynesian Economics and Price Theory: Re-orientation of a Theory of Monetary Economy. Springer. https://doi.org/10.1007/978-4-431-55345-8

Otaki, M. (2015b). Public debt as a burden on the future generation: A Keynesian approach. Theoretical Economics Letters, 5, 651-658. https://doi.org/10.4236/tel.2015.55076

Randall Wray, L. (2015). Modern Money Theory: A Primer on Macroeconomics for Sovereign Monetary Systems (2nd ed.). Palgrave Macmillan.

\section{Note}

Note 1. "I will discuss three major claims in TDM (The Deficit Myth) that I believe are mistaken...” (Hogan, 2021).

\section{Appendix A. Utility maximization of consumers}

The consumption baskets and their prices are

$$
\begin{gathered}
C_{1}^{e}=\left(\int_{0}^{1} c_{1}^{e}(z)^{\frac{\sigma-1}{\sigma}} d z\right)^{\frac{\sigma}{\sigma-1}}, C_{2}^{e}=\left(\int_{0}^{1} c_{2}^{e}(z)^{\frac{\sigma-1}{\sigma}} d z\right)^{\frac{\sigma}{\sigma-1}}, \\
C_{1}^{u}=\left(\int_{0}^{1} c_{1}^{u}(z)^{\frac{\sigma-1}{\sigma}} d z\right)^{\frac{\sigma}{\sigma-1}}, C_{2}^{u}=\left(\int_{0}^{1} c_{2}^{u}(z)^{\frac{\sigma-1}{\sigma}} d z\right)^{\frac{\sigma}{\sigma-1}},
\end{gathered}
$$

and 


$$
P_{1}=\left(\int_{0}^{1} p_{1}(z)^{1-\sigma} d z\right)^{\frac{1}{1-\sigma}}, P_{2}=\left(\int_{0}^{1} p_{2}(z)^{1-\sigma} d z\right)^{\frac{1}{1-\sigma}}
$$

The budget constraint for an employed consumer is

$$
\int_{0}^{1} p_{1}(z) c_{1}^{e}(z) d z+\int_{0}^{1} p_{2}(z) c_{2}^{e}(z) d z=W l+\Pi .
$$

The budget constraint for an unemployed consumer is

$$
\int_{0}^{1} p_{1}(z) c_{1}^{u}(z) d z+\int_{0}^{1} p_{2}(z) c_{2}^{u}(z) d z=\Pi
$$

Their Lagrange functions are

$$
\begin{gathered}
\mathcal{L}^{e}=u\left(C_{1}^{e}, C_{2}^{e}\right)-\lambda\left(\int_{0}^{q} p_{1}(z) c_{1}^{e}(z) d z+\int_{0}^{q} p_{2}(z) c_{2}^{e}(z) d z-W l-\Pi\right), \\
\mathcal{L}^{u}=u\left(C_{1}^{u}, C_{2}^{u}\right)-\lambda\left(\int_{0}^{q} p_{1}(z) c_{1}^{u}(z) d z+\int_{0}^{q} p_{2}(z) c_{2}^{u}(z) d z-\Pi\right) .
\end{gathered}
$$

Now consider utility maximization for an employed consumer. The first order condition is

$$
\frac{\partial u\left(C_{1}^{e}, C_{2}^{e}\right)}{\partial C_{1}^{e}}\left(\int_{0}^{1} c_{1}^{e}(z)^{\frac{\sigma-1}{\sigma}} d z\right)^{\frac{1}{\sigma-1}} c_{1}^{e}(z)^{-\frac{1}{\sigma}}-\lambda p_{1}(z)=0
$$

and

$$
\frac{\partial u\left(C_{1}^{e}, C_{2}^{e}\right)}{\partial C_{2}^{e}}\left(\int_{0}^{1} c_{2}^{e}(z)^{\frac{\sigma-1}{\sigma}} d z\right)^{\frac{1}{\sigma-1}} c_{2}^{e}(z)^{-\frac{1}{\sigma}}-\lambda p_{2}(z)=0
$$

From these equations we get

$$
\begin{gathered}
\frac{\partial u\left(C_{1}^{e}, C_{2}^{e}\right)}{\partial C_{1}^{e}}\left(\int_{0}^{1} c_{1}^{e}(z)^{\frac{\sigma-1}{\sigma}} d z\right)^{\frac{1}{\sigma-1}} \int_{0}^{1} c_{1}^{e}(z)^{\frac{\sigma-1}{\sigma}} d z-\lambda \int_{0}^{1} p_{1}(z) c_{1}^{e}(z) d z=0, \\
\frac{\partial u\left(C_{1}^{e}, C_{2}^{e}\right)}{\partial C_{2}^{e}}\left(\int_{0}^{1} c_{2}^{e}(z)^{\frac{\sigma-1}{\sigma}} d z\right)^{\frac{1}{\sigma-1}} \int_{0}^{1} c_{2}^{e}(z)^{\frac{\sigma-1}{\sigma}} d z-\lambda \int_{0}^{1} p_{2}(z) c_{2}^{e}(z) d z=0 \\
\frac{\partial u\left(C_{1}^{e}, C_{2}^{e}\right)}{\partial C_{1}^{e}} C_{1}^{e}-\lambda \int_{0}^{1} p_{1}(z) c_{1}^{e}(z) d z=0
\end{gathered}
$$

and

$$
\frac{\partial u\left(C_{1}^{e}, C_{2}^{e}\right)}{\partial C_{2}^{e}} C_{2}^{e}-\lambda \int_{0}^{1} p_{2}(z) c_{2}^{e}(z) d z=0 .
$$

From (A.1) and (A.2), we obtain 


$$
\begin{aligned}
& \left(\frac{\partial u\left(C_{1}^{e}, C_{2}^{e}\right)}{\partial C_{1}^{e}}\right)^{1-\sigma}\left(\int_{0}^{1} c_{1}^{e}(z)^{\frac{\sigma-1}{\sigma}} d z\right)^{-1} \int_{0}^{1} c_{1}^{e}(z)^{\frac{\sigma-1}{\sigma}} d z-\lambda^{1-\sigma} \int_{0}^{1} p_{1}(z)^{1-\sigma} d z=0 \\
& \left(\frac{\partial u\left(C_{1}^{e}, C_{2}^{e}\right)}{\partial C_{2}^{e}}\right)^{1-\sigma}\left(\int_{0}^{1} c_{2}^{e}(z)^{\frac{\sigma-1}{\sigma}} d z\right)^{-1} \int_{0}^{1} c_{2}^{e}(z)^{\frac{\sigma-1}{\sigma}} d z-\lambda^{1-\sigma} \int_{0}^{1} p_{2}(z)^{1-\sigma} d z=0
\end{aligned}
$$

and

$$
\frac{\partial u\left(C_{1}^{e}, C_{2}^{e}\right)}{\partial C_{1}^{e}}-\lambda\left(\int_{0}^{1} p_{1}(z)^{1-\sigma} d z\right)^{\frac{1}{1-\sigma}}=0, \frac{\partial u\left(C_{1}^{e}, C_{2}^{e}\right)}{\partial C_{2}^{e}}-\lambda\left(\int_{0}^{1} p_{2}(z)^{1-\sigma} d z\right)^{\frac{1}{1-\sigma}}=0 .
$$

They are rewritten as

$$
\frac{\partial u\left(C_{1}^{e}, C_{2}^{e}\right)}{\partial C_{1}^{e}}=\lambda P_{1}, \frac{\partial u\left(C_{1}^{e}, C_{2}^{e}\right)}{\partial C_{2}^{e}}=\lambda P_{2}
$$

Further, from (A.3) and (A.4), we have

$$
P_{1} C_{1}^{e}=\int_{0}^{1} p_{1}(z) c_{1}^{e}(z) d z, P_{2} C_{2}^{e}=\int_{0}^{1} p_{2}(z) c_{2}^{e}(z) d z
$$

By the budget constraint,

$$
P_{1} C_{1}^{e}+P_{2} C_{2}^{e}=W l+\Pi .
$$

(A.5) is a condition for maximization of $u\left(C_{1}^{e}, C_{2}^{e}\right)$ under the constraint (A.6). We can show similar results for an unemployed consumer. Since $u\left(C_{1}^{e}, C_{2}^{e}\right)$ and $u\left(C_{1}^{u}, C_{2}^{u}\right)$ are homothetic,

$$
\alpha=\frac{P_{1} C_{1}^{e}}{P_{1} C_{1}^{e}+P_{2} C_{2}^{e}}, 1-\alpha=\frac{P_{1} C_{1}^{e}}{P_{1} C_{1}^{e}+P_{2} C_{2}^{e}}
$$

are determined by the prices, and do not depend on the income. Thus, we get

$$
\alpha=\frac{P_{1} C_{1}^{e}}{P_{1} C_{1}^{e}+P_{2} C_{2}^{e}}=\frac{P_{1} C_{1}^{u}}{P_{1} C_{1}^{u}+P_{2} C_{2}^{u}}, 1-\alpha=\frac{P_{1} C_{1}^{e}}{P_{1} C_{1}^{e}+P_{2} C_{2}^{e}}=\frac{P_{1} C_{1}^{u}}{P_{1} C_{1}^{u}+P_{2} C_{2}^{u}} .
$$

From these calculations, the demand functions for consumption baskets are

$$
\begin{gathered}
C_{1}^{e}=\frac{\alpha(W l+\Pi)}{P_{1}}, C_{2}^{e}=\frac{(1-\alpha)(W l+\Pi)}{P_{2}}, \\
C_{1}^{u}=\frac{\alpha \Pi}{P_{1}}, C_{2}^{u}=\frac{(1-\alpha) \Pi}{P_{2}} .
\end{gathered}
$$

By (A.1), (A.2), (A.5), we have

$P_{1}\left(\int_{0}^{1} c_{1}^{e}(z)^{\frac{\sigma-1}{\sigma}} d z\right)^{\frac{1}{\sigma-1}} c_{1}^{e}(z)^{-\frac{1}{\sigma}}-p_{1}(z)=0, P_{2}\left(\int_{0}^{1} c_{2}^{e}(z)^{\frac{\sigma-1}{\sigma}} d z\right)^{\frac{1}{\sigma-1}} c_{2}^{e}(z)^{-\frac{1}{\sigma}}-p_{2}(z)=0$.

They mean

$P_{1}^{-\sigma}\left(\int_{0}^{1} c_{1}^{e}(z)^{\frac{\sigma-1}{\sigma}} d z\right)^{-\frac{\sigma}{\sigma-1}} c_{1}^{e}(z)-p_{1}(z)^{-\sigma}=0 \quad, \quad P_{2}^{-\sigma}\left(\int_{0}^{1} c_{2}^{e}(z)^{\frac{\sigma-1}{\sigma}} d z\right)^{-\frac{\sigma}{\sigma-1}} c_{2}^{e}(z)-$ 
$p_{2}(z)^{-\sigma}=0$.

Therefore,

$$
P_{1}^{-\sigma} \frac{1}{C_{1}^{e}} c_{1}^{e}(z)-p_{1}(z)^{-\sigma}=0, P_{2}^{-\sigma} \frac{1}{C_{2}^{e}} c_{2}^{e}(z)-p_{2}(z)^{-\sigma}=0
$$

From (A.7) the demand function for good $\mathrm{z}$ is

$$
c_{1}^{e}(z)=\left(\frac{p_{1}(z)}{P_{1}}\right)^{-\sigma} \frac{\alpha(W l+\Pi)}{P_{1}}, c_{2}^{e}(z)=\left(\frac{p_{2}(z)}{P_{2}}\right)^{-\sigma} \frac{\alpha(W i+\Pi)}{P_{1}} .
$$

For an unemployed consumer, from (A.8) we obtain

$$
c_{1}^{u}(z)=\left(\frac{p_{1}(z)}{P_{1}}\right)^{-\sigma} \frac{\alpha \Pi}{P_{1}}, c_{2}^{u}(z)=\left(\frac{p_{2}(z)}{P_{2}}\right)^{-\sigma} \frac{\alpha \Pi}{P_{1}} .
$$

\section{Appendix B. About a Model With Consumption in the Childhood Period and Pay-As-You-Go Pensions}

In this appendix we briefly consider a three-generations OLG model with consumption in the childhood period and pay-as-you-go pensions. Put Period 0 before Period 1 . It is the childhood period. In this period consumers do not work, only consume. The consumption could be thought of as education. This can be financed by borrowing from the younger generation or by government scholarships. No decisions are made during the childhood period, and the consumption is a constant common to all. Denote the consumption in the childhood period by $D$. The funds for consumption in the childhood period of consumers become debt, which must be repaid in their younger period. However, if they become unemployed, they will not be able to repay the debt, and the government will provide unemployment insurance in an amount equivalent to the debt. This is financed by the tax to the younger generation who are working. On the other hand, an older generation consumer will be able to receive a pension. This will be also financed by tax to the younger generation. Decisions about consumption in Periods 1 and 2 are made at the beginning of Period 1, as before, depending on whether the consumer is employed or unemployed. $G^{t}$ and $T^{t}$ represent government expenditure and tax other than pension and unemployment insurance.

Let $Q$ be the pension per consumer of the older generation, $\Psi$ be the pension tax to an employed consumer of the younger generation. Then,

$$
L_{f} Q=L \Psi
$$

This means

$$
\Psi=\frac{L_{f}}{L} Q
$$

Let $\Theta$ the tax for unemployment insurance to the younger generation consumers. Then,

$$
\left(L_{f}-L\right) D=L \Theta .
$$


This means

$$
\Theta+D=\frac{L_{f}}{L} D
$$

Let $\tilde{Q}$ be the pension received by a younger generation consumer in their older period. The budget constraint for an employed consumer is

$$
\begin{gathered}
\int_{0}^{1} p_{1}(z) c_{1}^{e}(z) d z+\int_{0}^{1} p_{2}(z) c_{2}^{e}(z) d z=W l+\Pi+\tilde{Q}-\Psi-\Theta-D \\
=W l+\Pi+\tilde{Q}-\frac{L_{f}}{L} Q-\frac{L_{f}}{L} D,
\end{gathered}
$$

or

$$
P_{1} C_{1}^{e}+P_{2} C_{2}^{e}=W l+\Pi+\tilde{Q}-\Psi-\frac{L_{f}}{L} Q-\frac{L_{f}}{L} D
$$

Since the debt is offset by the unemployment insurance, the budget constraint for an unemployed consumer is

$$
\int_{0}^{1} p_{1}(z) c_{1}^{u}(z) d z+\int_{0}^{1} p_{2}(z) c_{2}^{u}(z) d z=\Pi+\tilde{Q}
$$

or

$$
P_{1} C_{1}^{u}+P_{2} C_{2}^{u}=\Pi+\tilde{Q}
$$

From these results we can obtain the demand functions for consumption baskets and for each good. In this case from (B.1) and (B.2), (4) is written as

$$
P_{1}^{t} L_{f} l\left(L_{f}\right) y=\alpha\left(P_{1}^{t} L_{f} l\left(L_{f}\right) y+L_{f} \widetilde{Q}-L_{f} Q-L_{f} D-T^{t}\right)+L_{f} \widetilde{D}+G^{t}+M^{t}
$$

$\widetilde{D}$ is the consumption of the next generation consumers in their childhood period. It constitutes the effective demand as well as the government expenditure. Since when the economy grows, $\widetilde{Q}=\gamma Q$ and $\widetilde{D}=\gamma D$. The savings of the younger generation consumers (including the pensions received in the future) is

$$
\begin{aligned}
M^{t+1} & =(1-\alpha)\left(P_{1}^{t} L_{f} l\left(L_{f}\right) y+L_{f} \gamma Q-L_{f} Q-L_{f} D-T^{t}\right) \\
& =G^{t}-T^{t}+L_{f} \gamma Q-L_{f} Q+L_{f} \gamma D-L_{f} D+M^{t}
\end{aligned}
$$

Under economic growth, this equals $\gamma M^{t}$. Then, we need

$$
G^{t}-T^{t}=(\gamma-1)\left(M^{t}-L_{f} Q-L_{f} D\right) .
$$

Therefore, if the difference between the savings (excluding pensions) and the debt is positive, we need budget deficit. 
On the other hand, (7) is rewritten as

$$
\hat{P}_{1}^{t} L_{f} l\left(L_{f}\right) y=\alpha\left(P_{1}^{t} L_{f} l\left(L_{f}\right) y+L_{f} \tilde{Q}-L_{f} Q-L_{f} D-\widehat{T}^{t}\right)+L_{f} \widetilde{D}+\hat{G}^{t}+M^{t}
$$

Let $\eta=\frac{\hat{P}_{1}^{t}}{P_{1}^{t}}>1, \widetilde{Q}=\gamma \eta Q, \widetilde{D}=\gamma \eta D$. The savings of the younger generation consumers is

$$
\begin{aligned}
\widehat{M}^{t+1} & =(1-\alpha)\left(\hat{P}_{1}^{t} L_{f} l\left(L_{f}\right) y+L_{f} \gamma \eta Q-L_{f} Q-L_{f} D-\widehat{T}^{t}\right) \\
& =\hat{G}^{t}-\hat{T}^{t}+L_{f} \gamma \eta Q-L_{f} Q+L_{f} \gamma \eta D+M^{t} .
\end{aligned}
$$

Since under growth this equals $\gamma \eta M^{t}$, from

$$
\hat{G}^{t}-\widehat{T}^{t}=(\gamma \eta-1)\left(M^{t}-L_{f} Q-L_{f} D\right)>G^{t}-T^{t}=(\gamma-1)\left(M^{t}-L_{f} Q-L_{f} D\right),
$$

we have

$$
\eta-1=\frac{\left(\hat{G}^{t}-\hat{T}^{t}\right)-\left(G^{t}-T^{t}\right)}{\gamma\left(M^{t}-L_{f} Q-L_{f} D\right)}>0
$$

Thus, if $M^{t}-L_{f} Q-L_{f} D>0$, the excessive budget deficit causes inflation.

(9) is rewritten as

$$
P_{1}^{t} L l(L) y=\alpha\left(P_{1}^{t} L l y+L_{f} \gamma Q-L_{f} Q-L_{f} D-T^{t}\right)+\hat{G}^{t}+L_{f} \gamma D+M^{t}
$$

Comparing this with (B.3) yields

$$
L l(L)-L_{f} l\left(L_{f}\right)=\frac{\hat{G}^{t}-G^{t}}{(1-\alpha) P_{1}^{t} y} .
$$

This is equivalent to (10). The savings of the younger generation consumers is

$$
\begin{aligned}
\widehat{M}^{t+1} & =(1-\alpha)\left(P_{1}^{t} L l y+L_{f} \gamma Q-L_{f} Q-L_{f} D-T^{t}\right) \\
& =\hat{G}^{t}+L_{f} \gamma Q-L_{f} Q-T^{t}+L_{f} \gamma D-L_{f} D+M^{t}
\end{aligned}
$$

(11) is rewritten as

$$
\begin{gathered}
P_{1}^{t} L_{f} \gamma l\left(L_{f} \gamma\right) y=\alpha\left(P_{1}^{t} L_{f} \gamma l\left(L_{f} \gamma\right) y+L_{f} \gamma^{2} Q-L_{f} \gamma Q-L_{f} \gamma D-\gamma T^{t}\right) \\
+\hat{\hat{G}}^{t+1}+L_{f} \gamma^{2} D+\widehat{M}^{t+1}
\end{gathered}
$$

Thus, the savings of the younger generation consumers in Period $t+1$ is 


$$
\begin{aligned}
M^{t+2} & =(1-\alpha)\left(P_{1}^{t} L_{f} \gamma l\left(L_{f} \gamma\right) y+\gamma^{2} L_{f} Q-\gamma L_{f} Q-L_{f} \gamma D-\gamma T^{t}\right) \\
& =\hat{\hat{G}}^{t+1}+\gamma^{2} L_{f} Q-\gamma L_{f} Q-\gamma T^{t}+L_{f} \gamma^{2} D-L_{f} \gamma D+\widehat{M}^{t+1}
\end{aligned}
$$

Since this must equal $\gamma^{2} M^{t}$ to achieve full employment in Period $t+1$, from

$$
\begin{gathered}
\hat{G}^{t+1}+L_{f} \gamma^{2} Q-\gamma L_{f} Q-\gamma T^{t}+L_{f} \gamma^{2} D-L_{f} \gamma D+\widehat{G}^{t}+L_{f} \gamma Q-L_{f} Q-T^{t}+L_{f} \gamma D-L_{f} D+ \\
M^{t}=\gamma^{2} M^{t} .
\end{gathered}
$$

we have

$$
\begin{aligned}
& \hat{G}^{t+1}-\gamma T^{t}+\hat{G}^{t}-T^{t}=\left(\gamma^{2}-1\right)\left(M^{t}-L_{f} Q-L_{f} D\right) \\
= & \gamma(\gamma-1)\left(M^{t}-L_{f} Q-L_{f} D\right)+(\gamma-1)\left(M^{t}-L_{f} Q-L_{f} D\right) .
\end{aligned}
$$

Therefore, if $M^{t}-L_{f} Q-L_{f} D>0$ and $\hat{G}^{t}-T^{t}<(\gamma-1)\left(M^{t}-L_{f} Q-L_{f} D\right)$, we have

$$
\hat{\hat{G}}^{t+1}-\gamma T^{t}>\gamma(\gamma-1)\left(M^{t}-L_{f} Q-L_{f} D\right) .
$$

This means that if $M^{t}-L_{f} Q-L_{f} D>0$, an additional budget deficit is necessary to eliminate involuntary unemployment caused by insufficient budget deficit and to restore full employment.

In addition, it is possible to not collect taxes for pensions and unemployment insurance, in which case $G^{t}$ should be increased by that amount or decrease the value of $T^{t}$ by that amount. Of course, even in this case, it is impossible to maintain economic growth without causing inflation unless the budget deficit is kept at a certain level.

\section{Appendix C. Flow of Money}

Let us summarize the money flows for a general model that includes pensions and consumption in the childhood period. Assume that there is no scholarship by the government.

\section{Payment of money}

P1: consumption expenditure by the younger generation and the older generation consumers

P2: payment of wages and profits by firms

P3: payment of tax (other than pension tax) by the younger generation consumers

P4: government expenditure other than pensions

P5: consumption expenditure by the childhood generation consumers

P6: lending by the younger generation consumers to the childhood generation consumers 


\section{Macrothink}

International Journal of Social Science Research

ISSN 2327-5510 2022, Vol. 10, No. 1

P7: debt repayment by the younger generation consumers to the older generation consumers

P8: payment of pensions by the government

P9: payment of tax by the younger generation consumers for pensions

P10: payment of unemployment insurance by the government

P11: payment of tax by the younger generation consumers for unemployment insurance

\section{Receipt of money}

$\mathrm{R} 1$ : receipt of sales by firms

R2: receipt of wages and profits by the younger generation consumers

$\mathrm{R} 3$ : receipt of tax (other than pension tax) by the government

R4: borrowing by the childhood generation consumers from the younger generation consumers

R5: debt repayment from the younger generation consumers to the older generation consumers

R6: receipt of pensions by the older generation consumers

R7: receipt of tax by the government for pensions

R8: receipt of unemployment insurance by the older generation consumers

R9: receipt of tax by the government for unemployment insurance

Then, since

$\mathrm{P} 1+\mathrm{P} 4+\mathrm{P} 5=\mathrm{R} 1, \mathrm{P} 2=\mathrm{R} 2, \mathrm{P} 3=\mathrm{R} 3, \mathrm{P} 6=\mathrm{R} 4, \mathrm{P} 7=\mathrm{R} 5, \mathrm{P} 8=\mathrm{R} 6, \mathrm{P} 9=\mathrm{R} 7, \mathrm{P} 10=\mathrm{R} 8, \mathrm{P} 11=\mathrm{R} 9$

hold, the total payment equals the total receipt, that is,

$$
\begin{array}{r}
\mathrm{P} 1+\mathrm{P} 2+\mathrm{P} 3+\mathrm{P} 4+\mathrm{P} 5+\mathrm{P} 6+\mathrm{P} 7+\mathrm{P} 8+\mathrm{P} 9+\mathrm{P} 10+\mathrm{P} 11 \\
=\mathrm{R} 1+\mathrm{R} 2+\mathrm{R} 3+\mathrm{R} 4+\mathrm{R} 5+\mathrm{R} 6+\mathrm{R} 7+\mathrm{R} 8+\mathrm{R} 9 .
\end{array}
$$

Also, since

$$
\mathrm{P} 2=\mathrm{R} 1, \mathrm{P} 5=\mathrm{P} 6=\mathrm{R} 4, \mathrm{P} 8=\mathrm{P} 9=\mathrm{R} 6=\mathrm{R} 7, \mathrm{P} 10=\mathrm{P} 11=\mathrm{R} 8=\mathrm{R} 9, \mathrm{P} 7=\mathrm{R} 5,
$$

we have

$$
\mathrm{P} 1+\mathrm{P} 3+\mathrm{P} 4+\mathrm{P} 6=\mathrm{R} 2+\mathrm{R} 3 .
$$

On the other hand, let

M1: savings of the older generation consumers carried over from the previous period (excluding repayment from the younger generation consumers)

M2: savings of the younger generation consumers (excluding lending to the childhood generation consumers) 
Then,

payment of consumption by the older generation consumers $=\mathrm{M} 1+\mathrm{R} 5+\mathrm{R} 6$, and

$$
\mathrm{R} 2+\mathrm{R} 8=\text { consumption expenditure of the younger generation consumers }
$$

$+\mathrm{P} 3+\mathrm{P} 6+\mathrm{P} 7+\mathrm{P} 9+\mathrm{P} 11+\mathrm{M} 2$.

From these equations, and P9 $=\mathrm{R} 6, \mathrm{P} 7=\mathrm{R} 5, \mathrm{P} 11=\mathrm{R} 8$, we obtain

$\mathrm{R} 2=\mathrm{P} 1+\mathrm{P} 3+\mathrm{P} 6+\mathrm{P} 7+\mathrm{P} 9+\mathrm{M} 2-\mathrm{M} 1-\mathrm{R} 5-\mathrm{R} 6=\mathrm{P} 1+\mathrm{P} 3+\mathrm{P} 6+\mathrm{M} 2-\mathrm{M} 1$.

This and (C.1) yield

$$
\mathrm{P} 4-\mathrm{R} 3=\mathrm{M} 2-\mathrm{M} 1 .
$$

Therefore, an increase in the savings equals the budget deficit. If the government does not collect taxes for pensions or unemployment insurance, we can decrease R3 or increase P4 by that amount.

\section{Copyrights}

Copyright for this article is retained by the author(s), with first publication rights granted to the journal.

This is an open-access article distributed under the terms and conditions of the Creative Commons Attribution license (http://creativecommons.org/licenses/by/4.0/). 